\title{
Effects of Skepticism on Consumer Response toward Cause-related Marketing in Malaysia
}

\author{
Marhana Mohamed Anuar ${ }^{1} \&$ Osman Mohamad $^{2}$ \\ ${ }^{1}$ Faculty of Management and Economics, Universiti Malaysia Terengganu, Terengganu, Malaysia \\ ${ }^{2}$ Graduate School of Business, Universiti Sains Malaysia, Penang, Malaysia \\ Correspondence: Marhana Mohamed Anuar, Faculty of Management and Economics, Universiti Malaysia \\ Terengganu, 21030, K. Terengganu, Malaysia. Tel: 60-9-668-3290. E-mail: marhana@umt.edu.my
}

Received: February 17, 2012

Accepted: July 9, $2012 \quad$ Online Published: August 8, 2012

doi:10.5539/ibr.v5n9p98

URL: http://dx.doi.org/10.5539/ibr.v5n9p98

\begin{abstract}
Cause-related marketing (CRM) is a marketing tool that brings benefits to a sponsoring company, a cause and a consumer. Companies all over the world are showing greater interest in CRM because of the plethora of benefits it brings to key stakeholders and the increasing consumer concern over socially responsible consumption. However, despite the widespread adoption of CRM among companies, consumers may view CRM with skepticism. Using a survey method, this study examined whether or not Malaysians are skeptical toward CRM. Further, this study examined the impact of consumer skepticism on attitude toward and evaluation of CRM. The results showed that, in general, consumer skepticism toward CRM falls in the middle range. The results also showed that consumer skepticism significantly influences attitude toward CRM and CRM evaluation. Thus, some issues need to be taken into consideration by companies in order to reduce the level of consumer skepticism toward CRM.
\end{abstract}

Keywords: cause-related marketing, consumer skepticism, Malaysia

\section{Introduction}

Today's consumers are becoming increasingly concerned over environmental and social issues such as conservation of the environment, recycling, poverty and education of the poor. This has influenced and shaped their consumption patterns. Consumption patterns that take into consideration the impact of consumption on environmental and social issues can be considered as socially responsible forms of consumption. Cause-related marketing (CRM) enables consumers to make a difference in society through their purchases. In line with this, there has been increasing interest in the adoption of CRM campaigns among companies in many parts of the world. According to IEG Sponsorship, spending on cause-partnerships was expected to reach USD1.55 billion in 2009, a 2.2\% increase from the previous year (IEG Sponsorship Report, 2009).

In Western countries, especially in the United States of America (USA) and in the United Kingdom (UK), CRM campaigns have been widely used as a promotional tool to increase sales and to raise funds for causes. Indeed, CRM has been used as an important promotional tool for more than 20 years. The first CRM campaign is believed to have been conducted by American Express in 1983; the campaign was conducted to raise funds to restore the Statue of Liberty (Adkins, 2000; Pringle \& Thompson, 2001). CRM has now evolved from being a promotional tool to a strategic tool that is tied directly to corporate strategies. In Malaysia, CRM is becoming more and more popular; many companies such as Kentucky Fried Chicken (KFC), Colgate, The Loving Company (TLC) and Body Shop have used CRM campaigns to increase sales and at the same time contribute to several causes. This means that each time a consumer purchases a CRM product, a proportion of that spend is donated to a cause. For example, since 2006, KFC has conducted CRM campaigns to support World Hunger Relief Funds to help support poor people all over the world. In this campaign, a proportion of the purchase price for certain KFC menu items is donated to the World Hunger Relief Funds. Cause-related marketing allows consumers to express their concerns about environmental and social issues such as environmental conservation, hunger, poverty, education for poor children and support for disabled people through their purchases in grocery stores or supermarkets at no additional cost to them in terms of time and money. 
An important issue that has arisen in respect of the increasing trend toward socially responsible consumption among consumers and the widespread use of CRM in many parts of the world is whether or not consumers view CRM with skepticism. Consumer skepticism makes consumers doubt or question a company's claims regarding its involvement in trying to improve or mitigate social and environmental issues. Previous studies point out that in a country where CRM is widely used, such as in the USA, consumer skepticism toward CRM is declining (e.g., Webb \& Mohr, 1998). In addition, previous studies suggest that consumers in countries where CRM is less established have a less positive attitude toward CRM (Lavack \& Kropp, 2003; Singh et al., 2009). Consumer skepticism toward CRM is a challenge for companies investigating the possibility of implementing CRM. This is because CRM tends to be viewed with skepticism because a donation to a particular cause is linked with a purchase of a product (Singh et al., 2009). Thus, consumers often perceive CRM as an exploitation of a cause for a company's self-interest (Cui et al., 2003; Forehand \& Grier, 2003). Past research suggests that skepticism affects consumer response to CRM campaigns (Bronn \& Vrioni, 2001; Pirsch et al., 2007; Singh et al., 2009; Webb \& Mohr, 1998). Moreover, consumer skepticism could lead to rejection of the CRM claims made in CRM campaigns (Bronn \& Vrioni, 2001) and could affect the purchasing behavior of consumers (Gupta \& Pirsch, 2007).

Since CRM is becoming more prevalent in Malaysia, it is crucial to gain an understanding of the level of Malaysian consumer skepticism toward CRM. In relation to this issue, this study aimed to answer two questions: First, are Malaysian consumers skeptical toward CRM campaigns? Second, what is the impact of consumer skepticism toward CRM on attitude toward and evaluation of CRM campaigns?

The study of these issues is essential considering the widespread adoption of CRM among companies and lack of empirical evidence on the level of consumer skepticism toward CRM in Malaysia. This study will extend the application of Signaling Theory (Spence, 1973) to the context of CRM. The results of this study will also provide important information for marketers and managers who are involved in CRM campaigns in Malaysia and in other countries where CRM is a new concept. In this paper, first an overview of CRM is presented together with a definition thereof. Second, a definition of skepticism is given and the impact of consumer skepticism toward CRM on consumer behavior variables is discussed. Third, the methodology used in this study is presented. Fourth and fifth, the results and a detailed discussion thereof are provided. The paper concludes with a discussion of the theoretical and managerial implications of the findings and the study limitations and suggestions for future research.

\section{Cause-related Marketing: An Overview}

This study combines Signaling Theory and the Persuasion Knowledge Model (PKM) to explain the influence of consumer skepticism on the response toward CRM. Signaling theory suggests that consumers use cues to form their judgments about objects (Spence, 1973). If we apply signaling theory to the context of this study, it can be considered that consumers use the messages of cause claims that appear in CRM advertisements as a signal or cue to form their judgments about CRM campaigns. According to the PKM (Friestad \& Wright, 1995, p. 62), consumers draw on their persuasion beliefs when interpreting and responding to marketers' persuasion attempts (e.g., advertising that has social dimensions such as CRM campaigns). In the context of CRM, it can be suggested that consumers' persuasion beliefs regarding CRM can be very much influenced by their knowledge and feelings of skepticism toward CRM campaigns. Therefore, it is predicted that consumer knowledge and consumer skepticism influence the interpretation of signals (cause claims) in CRM advertisements.

\subsection{Cause-related Marketing}

Cause-related marketing is a type of corporate social responsibility (CSR) initiative. Cause-related marketing is more prevalent today because CRM is able to enhance corporate image and profits as well as increase funds for a multitude of causes. Cause-related marketing has been defined as: "the process of formulating and implementing marketing activities that are characterized by an offer from firm to contribute a specified amount to a designated cause when customers engage in revenue-providing exchanges that satisfy organizational and individual objectives" (Varadarajan \& Menon, 1988, p. 60).

Varadarajan and Menon's definition of CRM suggests that a company's donation to a cause is linked with a purchase of a certain product. This definition focuses on the transaction-based CRM implementation. Liu and Ko (2011) suggest that transaction-based CRM refers to corporations donations to a specific charity is based on a portion of profits from each product sold (p. 255). Cause-related marketing campaigns allow consumers to donate to a cause because, for every purchased of a certain product, a proportion of its sale price is donated to a cause. 
A review of past literature showed that many researchers use the definition of Varadarajan and Menon (1988). One possible reason for the widespread acceptance of this definition among researchers could be due to the fact that it aptly describes the unique marriage of philanthropy and profit. Through CRM, companies can gain profit because consumers are attracted to buy a "product with a heart". Cause-related marketing brings benefits to a company, a cause and a consumer. CRM can enhance a company's image, increase product sales and profit (Varadarajan \& Menon, 1986); a cause can receive greater funding and enhanced publicity (Berglind \& Nakata, 2005); and a CRM product purchase provides a consumer with an opportunity to donate to a cause in a way that is simple and convenient (Langen, Grebitus, \& Hartmann, 2010).

Much of the academic research on consumer response to CRM emerged following the seminal work on CRM by Varadarajan and Menon (1988). Academic research on CRM has covered the effect of CRM on consumer behavior variables such as purchase intention (e.g., Moosmayer \& Fuljahn, 2010), brand loyalty (Brink et al., 2006) and attitude toward CRM (Cui et al., 2003; Sheikh \& Beise-Zee, 2011). Most of the previous studies have found that the effect of CRM on consumer response variables is positive. However, previous studies (e.g., Webb \& Mohr, 1998; Singh et al., 2009) have also suggested that consumer skepticism could result in a negative response toward CRM. However, an extensive review of the literature revealed that studies on the effect of consumer skepticism on consumer response to CRM remain scarce.

\subsection{Consumer Skepticism toward Cause-related Marketing}

Consumer skepticism is defined as consumers' tendency to disbelieve or question a company's motivation to conduct a CRM program (Mohr, Eroglu, \& Ellen, 1998). Skepticism toward advertising is the general tendency of disbelief about advertising claims; it represents a basic marketplace belief that varies across persons and is related to general persuasability (Obermiller \& Spangenberg, 1998, p. 159).

In the CRM context, for every CRM campaign conducted, brands or companies often make claims about their support for or involvement in social and environmental issues. These claims can be viewed with skepticism by consumers. Consumer skepticism can lead consumers to respond negatively to CRM campaigns. In general, a highly skeptical consumer will perceive the accuracy of a CRM claim to be low. In contrast, a consumer with a low level of skepticism will perceive the accuracy of a CRM claim to be higher. Additionally, consumer skepticism toward CRM can increase if CRM campaigns are heavily advertised in the media (Singh et al., 2009).

Previous studies suggest that consumer skepticism plays an important role in influencing consumer response to CRM (e.g., Bronn \& Vrioni, 2001; Gupta \& Pirsch, 2006; Singh et al., 2009; Webb \& Mohr, 1998). Webb and Mohr (1998) indicate that a consumer's interpretation of CRM could depend on the level of skepticism that they have regarding the cause claims in CRM campaigns. Consumer skepticism about CRM can occur because (1) consumers often question cause claims because they are skeptical about a company's motive for conducting CRM campaigns and (2) consumers distrust CRM campaigns conducted by companies (Webb \& Mohr, 1998).

Previous studies suggest that there are two motives for companies conducting partnerships with causes: extrinsic and intrinsic motives (e.g., Cui, Trent, Sullivan, \& Matiru, 2003). Extrinsic motives are viewed with a higher level of skepticism than intrinsic motives. The reason for this appears to be that extrinsic motives can be perceived as egoistic or self-interested while intrinsic motives can be seen as altruistic or other-interested (Cui et al., 2003). More specifically, self-interested motives are more likely to be viewed with a higher degree of skepticism if a CRM campaign is perceived to be conducted mainly in order to generate higher sales and profits. On the other hand, other-interested motives can be viewed with a lower degree of skepticism because consumers perceive that a company's motive for conducting such a campaign is altruistic, i.e., to support a cause. In line with this, Singh et al. (2009) suggest that consumers tend to be skeptical toward CRM because a donation to a cause is linked to revenue generation. Consumers tend to believe that CRM campaigns are conducted because companies want to enhance their sales and generate more profits rather than help causes.

Consumers' distrust of CRM campaigns can also occur as a result of the small proportion amount of money of the purchase price donated to a particular cause for each purchase of CRM products (e.g., RM0.10). In general, large donations are perceived as more altruistic and real than small donations (Dahl \& Lavack, 1995). In addition, disclosing the amount of the donation to a cause in a particular CRM campaign can reduce consumer doubts about a company's motive for partnering with a cause. Webb and Mohr (1998) suggest that disclosing the amount of money being donated to a cause via CRM campaigns helps to reduce consumer doubt about whether or not the money raised is actually donated to a cause as promised.

Previous studies found that consumer skepticism can influence purchase intention (Barone et al., 2000; Gupta \& Pirsch, 2006; Szykman et al., 1997; Webb \& Mohr, 1998). Barone et al. (2000) suggest that a high degree of congruency between a sponsoring company and a cause can influence consumer skepticism. A high degree of 
congruency between a company and a cause generates a high degree of consumer skepticism. This is due to the perception that the company is exploiting rather than helping the cause (Barone et al., 2000). In contrast, Gupta and Pirsch (2006) found that consumer skepticism does not influence purchase intention. They suggest that consumers can perceive companies' motives for conducting CRM campaigns as altruistic motives and hence, they are willing to purchase CRM products.

Bronn and Vrioni (2001) surveyed Norwegian consumers and found that the level of skepticism among Norwegian consumers is rather high. This could be due to the newness of CRM in Norway at the time of the study. Some researchers have found that the level of consumer skepticism toward CRM is very much related to the level of awareness of CRM. Basically, a low level of awareness of CRM could result in high skepticism toward CRM. In the USA,where CRM has been used for more than 20 years, it is found that the level of consumer skepticism is low compared to when CRM was first introduced in the market. Past studies suggest that as consumers' knowledge about CRM increases their level of skepticism toward CRM decreases (Bronn \& Vrioni, 2001; Singh et al., 2009; Webb \& Mohr, 1998). Researchers suggest that skepticism is situational and not long lasting; it is suggested that skepticism decreases as knowledge increases (Bronn \& Vrioni, 2001; Mohr et al., 1998). Singh et al. (2009) examined the influence of claim repetition on consumer skepticism toward CRM. They found that claim repetition can reduce the level of consumer skepticism toward CRM. The results of their study demonstrate that, by repeating CRM claims, consumer awareness of CRM can be enhanced and can lead to a reduction in skepticism and a higher intention to purchase CRM products.

\section{Methodology}

\subsection{The Study Site and Sample}

The aim of the current study was to determine the level of consumer skepticism toward CRM in Malaysia. Consumer skepticism was examined through surveys on students. Students were chosen as the target group for this study for a number of reasons. First, students are an emerging potential market with powerful aggregate spending and can be considered as young enough to start establishing values and buying principles that may last a lifetime (Cui et al., 2003). Second, many of the products that are used in CRM campaigns conducted in Malaysia are convenience products (e.g., toothpaste, soap, detergent, cereal, coffee mix). These products are affordable and are frequently purchased by students. Third, previous studies have shown that consumers who support CRM tend to be young and educated (Barnes, 1992; Webb \& Mohr, 1998). Surveys were conducted on students at three public universities in Malaysia. The three universities from which the samples were drawn are located in three different states: Terengganu, Penang and Kedah. A total of 100 questionnaires were distributed at each university. Out of the 300 questionnaires distributed, 277 questionnaires were used in the data analyses; the others (23) were excluded due to answers being incomplete or all uniform. The characteristics of the respondents are shown in Table 1.

Table 1. Characteristics of Respondents $(\mathrm{N}=277)$

\begin{tabular}{lcc}
\hline & Frequency & \% \\
\hline Gender & 118 & \\
Male & 159 & 42.6 \\
Female & & 57.4 \\
Race & 188 & \\
Malay & 67 & 67.9 \\
Chinese & 12 & 24.2 \\
Indian & 10 & 4.3 \\
Others & & 3.6 \\
Major & 113 & \\
Business & 164 & 40.8 \\
Non-Business & & 59.2 \\
Program of Study & 250 & \\
Bachelor's & 25 & 90.3 \\
Master's & 2 & 9.0 \\
PhD/DBA & & 0.7 \\
\hline
\end{tabular}




\subsubsection{Measurements of Items}

The questionnaires consist of four sections: (1) a CRM advertisement - a color-print advertisement presenting a grocery store supporting a poverty cause through a CRM campaign; (2) skepticism toward CRM; (3) attitude toward CRM and CRM evaluation; and (4) demographic data. Attitude toward CRM was measured using three seven-point evaluative scales (bad/good, negative/positive and unfavorable/favorable). The construct that was used to measure attitude toward CRM was adapted from Cui et al. (2003). This three-item scale is commonly used to assess a respondent's overall attitude toward an event or an object. These three items have been used in previous studies and have been shown to be generalizable and adaptable (Cui et al., 2003; Osgood \& Tannenbaum, 1955).

The questions that were used to measure consumer skepticism were adapted from Mohr et al. (1998). The items used to measure consumer skepticism consisted of four items: (1) "Most statements made by a company in advertising or package labels about supporting a cause are true"; (2) "Most statements made by a company in advertising or on package labels about supporting a cause are intended to mislead rather than to inform the consumer"; (3) "Because most of the statements made by companies which say that they support causes are not true, consumers would be better off if such statements were eliminated from advertising or package labels"; and (4) "I do not believe most statements regarding support of a cause in advertising or on package labels." These items were measured using a seven-point scale ( 1 = strongly disagree to 7 = strongly agree).

The consumer evaluation of a CRM campaign, hereinafter CRM evaluation, was measured by using measurements adapted from Cui et al. (2003) and Ellen et al. (2000). The items that were used to measure CRM evaluation consisted of five seven-point evaluative scales (bad/good, unpleasant/pleasant, unfavorable/favorable, harmful/beneficial, foolish/wise).

\section{Results}

Descriptive statistics of the main variables are shown in Table 2. The results showed the respondents' skepticism level toward CRM $(M=4.01)$, attitude toward CRM $(M=5.71)$ and CRM evaluation $(M=5.51)$. So, are Malaysian consumers skeptical toward CRM campaigns? The results showed that the consumer skepticism level falls in the middle range. The results imply that the respondents, on average, are neither skeptical nor believe CRM claims. In addition, the results showed that, in general, the respondents have a favorable attitude toward CRM and evaluate CRM favorably.

Table 2. Descriptive Statistics of Main Variables

\begin{tabular}{lll}
\hline Variable & Mean & Std. Deviation \\
\hline Skepticism & 4.01 & 1.04 \\
Attitude & 5.71 & 1.07 \\
CRM evaluation & 5.51 & 0.98 \\
\hline
\end{tabular}

Note: All items used a seven-point scale.

What is the impact of consumer skepticism toward CRM on attitude toward and evaluation of CRM campaigns? In order to answer this question, an independent sample t-test was carried out. Prior to conducting the independent sample t-test, its assumptions were first checked. The independent sample t-test assumed that the dependent variable was normally distributed, the groups were independent in their response to the dependent variable and variances between groups were equal. Preliminary checks confirmed that these assumptions were fulfilled. Then, the aggregate score for each variable was computed. A mean split was conducted in order to divide the respondents into two groups: low skepticism and high skepticism. Respondent scores for skepticism below the mean $(<4.01)$ fall in the low skepticism group while respondent scores above the mean $(>4.01)$ fall in the high skepticism group. Next, the independent sample t-test was conducted on low and high consumer skepticism. The results are illustrated in Table 3, which shows the means for attitude toward CRM and CRM evaluation for both high skepticism and low skepticism respondents, along with the t-test values. The results suggest that there is a significant difference in attitude toward CRM and CRM evaluation between low skepticism and high skepticism respondents. Low skepticism respondents seemed to have a more favorable attitude toward CRM and evaluate CRM more favorably compared to respondents who have a high level of skepticism. 
Table 3. Independent Sample T-test of Consumer Skepticism

\begin{tabular}{cccccc}
\hline Variable & Consumer Skepticism & Mean & Std. Deviation & t & p(one-tailed) \\
\hline Attitude toward CRM & Low skepticism & 5.93 & 0.92 & 3.142 & 0.001 \\
& High skepticism & 5.53 & 1.16 & & \multirow{2}{*}{0.000} \\
CRM evaluation & Low skepticism & 5.76 & 0.79 & 3.996 & \\
& High skepticism & 5.32 & 1.02 & & \\
\hline
\end{tabular}

\section{Discussion}

In today's market, CRM can be used as a strategic tool to gain competitive advantage. In many parts of the world, CRM has become an important marketing tool for both companies and causes through which they can realize their objectives. However, the results of our study demonstrated that consumer skepticism toward CRM can be a major limiting factor in achieving a favorable response from consumers toward CRM. Basically, this study has two main findings. First, although CRM can be considered as still new in Malaysia compared to Western countries such as the USA and the UK, the results show that consumer skepticism is in the middle range. Second, the impact of consumer skepticism on attitude toward CRM and CRM evaluation is significant.

One possible reason why the results showed that consumers' skepticism is average could be due the fact that the majority of the respondents in this study are Malays. Malay culture highly values giving (Josie \& Ibrahim, 2002). In Malaysia, Malays are known for their generosity toward those in need (Josie \& Ibrahim, 2002). In addition, our results showed that consumers with a high level of skepticism tend to respond negatively toward CRM campaigns. In contrast, consumers with a low level of skepticism showed a favorable response toward CRM. More specifically, the latter showed a more positive attitude toward and evaluation of CRM. Our results support previous studies that propose that consumer skepticism influences consumer response to CRM (Bronn \& Vrioni, 2001; Webb \& Mohr, 1998). The results also show support toward PKM (Friestad \& Wright, 1995). The results provide empirical evidence that consumers' level of skepticism does influence their interpretation of cause claims in CRM advertisements. This study provides support for using PKM to examine the influence of skepticism on consumer response toward CRM in the Malaysian context.

Since consumer skepticism toward CRM significantly affects consumer response toward CRM, it is important for companies to have a good understanding of the level of consumer skepticism toward their CRM campaigns before implementing CRM campaigns. It is a fundamental prerequisite that a company have sufficient knowledge and understanding about the level of consumer skepticism toward CRM in general and toward a specific type of CRM campaign prior to implementing and designing a CRM campaign. Without this, CRM campaigns are unlikely to receive a favorable response from consumers and eventually are unlikely to succeed. This understanding of the level of consumer skepticism toward CRM as well the impact of skepticism on consumer response variables (e.g., attitude toward CRM, CRM evaluation, purchase intention) is crucial especially in countries where the CRM campaign is still a new concept, such as in Malaysia and other developing countries.

Research suggests that knowledge has a negative effect on a person's skepticism level (Szykman et al., 1997). This would imply that one of the initial steps that needs to be undertaken by marketers prior to conducting a CRM campaign is to communicate well to consumers details about the particular CRM campaign that is to be conducted and who or what causes benefits from the initiative. Based on Szykman et al. (1997), it is suggested that by increasing consumers' knowledge and awareness of CRM campaigns through communicating the CRM initiatives by using suitable media channels for the target market, the level of consumer skepticism among those targeted can be reduced. In addition, this will result in a more a favorable response toward CRM campaigns among the target market.

\section{Conclusions}

This study makes several theoretical and managerial contributions. This study contributes to the literature on CRM by providing empirical evidence about the level of consumer skepticism in Malaysia and the impact of consumer skepticism on consumer behavior such as attitude toward and evaluation of CRM campaigns. The results extend those of the study conducted by Singh et al. (2009) in that this study examined the impact of consumer skepticism on attitude toward CRM and CRM evaluation.

From a managerial perspective, by understanding the level of consumer skepticism toward CRM in a certain market, companies can develop strategies to reduce skepticism toward CRM among consumers. This is particularly important as this study provides empirical evidence that consumer skepticism toward CRM can be 
a key challenge and barrier to the success of CRM. Consumer skepticism toward CRM influences attitude toward as well evaluation of a particular CRM campaign. Companies need to communicate to consumers the details of their CRM campaigns, for instance, by providing clear information about how much has been raised by their previous campaigns and how they have helped their partner causes. This could help to reduce consumer skepticism toward CRM campaigns conducted by companies. However, companies should be cautioned not to communicate excessively because it could lead to the perception that their CRM campaigns are cause-exploitative rather than cause-beneficial.

Several limitations of this study need to be acknowledged; however, these limitations pose interesting questions for future research agenda. First, the major limitation of this study was the use of students as the sample. Future research could use a consumer sample instead of a student sample. Second, this research examined the level of consumer skepticism, but future research could examine the level of consumer awareness and the effect of that awareness on consumer skepticism and CRM evaluation. Third, further research could also attempt to identify the conditions that lead to reduce consumer skepticism and enhance response to CRM campaigns.

\section{Acknowledgements}

We are grateful to Universiti Malaysia Terengganu for sponsoring this research.

\section{References}

Adkins, S. (2000). Cause-related marketing: Who cares wins. Oxford: Elsevier Butterworth-Heinemann.

Barone, M. J., Miyazaki, A. D., \& Taylor, K. A. (2000). The influence of cause-related marketing on consumer choice: Does one good turn deserve another?. Journal of the Academy of Marketing Science, 28(spring), 248-262.

Barone, M. J., Norman, A. T., \& Miyazaki, A. D. (2007). Consumer response to retailer use of cause-related marketing: Is more fit better?. Journal of Retailing, 83(4), 437-445. http://dx.doi.org/10.1016/j.jretai.2007.03.006

Berglind, M., \& Nakata, C. (2005). Cause-related marketing: More buck than bang?. Business Horizons, 48, 443-453. http://dx.doi.org/10.1016/j.bushor.2005.04.008

Bronn, P. S., \& Vrioni, A. B. (2001). Corporate social responsibility and cause-related marketing: An overview. International Journal of Advertising, 20, 207-222.

Cui, Y., Trent, E. S., Sullivan, P. M., \& Matiru, G. N. (2003). Cause-related marketing: How generation Y responds. International Journal of Retail \& Distribution Management, 31(6), 310-320. http://dx.doi.org/10.1108/09590550310476012

Dahl, D. W., \& Lavack, A. M. (1995). Cause-related marketing: Impact of size of cause-related promotion on consumer perceptions and participation. American Marketing Association Educator's Winter Conference, pp. 476-481.

Ellen, P. S., Mohr, L. A., \& Webb, D. J. (2000). Charitable programs and the retailer: Do they mix?. Journal of Retailing, 76(3), 393-406. http://dx.doi.org/10.1016/S0022-4359(00)00032-4

Forehand, M. R., \& Grier, S. (2003). When is honesty the best policy? The effect of stated company intent on consumer skepticism. Journal of Consumer Psychology, 349-356.

Gupta, S., \& Pirsch, J. (2006). The company-cause-customer fit decision in cause-related marketing. Journal of Consumer Marketing, 23(6), 314-326. http://dx.doi.org/10.1108/07363760610701850

IEG. (2009, July 27). IEG Sponsorship Report. Retrieved February 03, 2011 from http://www.sponsorship.com.

Josie, M. F., \& Ibrahim, A. R. (2002). A Giving Society? The State of Philanthropy in Malaysia. Penang: Universiti Sains Malaysia.

Langen, N., Grebitus, C., \& Hartmann, M. (2010). Is there need for more transparancy and efficiency in cause-related marketing?. International Journal on Food System Dynamics, 366-381.

Liu, G., \& Ko, W. W. (2011). An analysis of cause-related marketing implementation strategies through social alliance: Partnership conditions and strategic objectives. Journal of Business Ethics, 100, 253-281. http://dx.doi.org/10.1007/s10551-010-0679-7

Mohr, L. A., Eroglu, D., \& Ellen, S. P. (1998). The development and testing of a measure of skepticism toward environment claims in marketers' communications. The Journal of Consumer Affairs, 32(1), 30-55. http://dx.doi.org/10.1111/j.1745-6606.1998.tb00399.x 
Moosmayer, D. C., \& Fuljahn, A. (2010). Consumer perceptions of cause-related marketing campaigns. Journal of Consumer Marketing, 27(6), 543-549. http://dx.doi.org/10.1108/07363761011078280

Obermiller, C., \& Spangenberg, E. R. (1998). Development of a scale to measure consumer skepticism toward $\begin{array}{lllll}\text { advertising. Journal of } & \text { Consumer } & \text { Psychology, } & 7(2), & 159-186 .\end{array}$ http://dx.doi.org/10.1207/s15327663jcp0702_03

Osgood, C. E., \& Tannenbaum, P. H. (1955). The principle of congruity in the prediction of attitude change. Psychological Review, 62, 42-55. http://dx.doi.org/10.1037/h0048153

Pringle, H., \& Thompson, M. (2001). How cause-related marketing builds brands. England: Wiley.

Sheikh, S. U. R., \& Beise-Zee, R. (2011). Corporate social responsibility or cause-related marketing? The role of cause specificity of CSR. Journal of Consumer Marketing, 28(1), 27-39. http://dx.doi.org/10.1108/07363761111101921

Singh, S., Kristensen, L., \& Villasenor, E. (2009). Overcoming skepticism towards cause-related claims: The case of Norway. International Marketing Review, 312-326. http://dx.doi.org/10.1108/02651330910960807

Szykman, R. L., Bloom, N. P., \& Levy, S. A. (1997). A proposed model of the use of package claims and nutrition labels. Journal of Public Policy \& Marketing, 16(2), 228-241.

Varadarajan, P. R., \& Menon, A. (1988). Cause-related marketing: A co-alignment of marketing strategy and corporate philanthropy. Journal of Marketing, 52(July), 58-74. http://dx.doi.org/10.2307/1251450

Webb, D. J., \& Mohr, L. A. (1998). A typology of consumer responses to cause-related marketing from skeptics to socially concerned. Journal of Public Policy \& Marketing, 17(2), 226-238.

Wymer, W., \& Samu, S. (2009). The influence of cause-marketing associations on product and cause brand value. International Journal of Nonprofit and Voluntary Sector Marketing, 14, 1-20. http://dx.doi.org/10.1002/nvsm.348 